Please cite as:

Brown, C.J. and N. Markusson (2019) The responses of older adults to smart energy monitors, Energy Policy 130: 218-226, doi.org/10.1016/i.enpol.2019.03.063

\title{
The responses of older adults to smart energy monitors
}

\section{Abstract}

By 2020, every UK household has the option to have a Smart Energy Monitor (SEM) installed, displaying electricity consumption monetarily. The success of the $f 11$ billion scheme in enabling people to reduce energy consumption is questioned amongst researchers and relatively little is known about older adults' (60+ years) responses to SEMs. This paper explores older adult responses to SEM feedback and compares them to those of younger-middle aged adults (25-59 years). A qualitative, interpretative methodology was used with participants from 20 households recording their SEM experiences during one month through a diary, and post-study semi-structured interview allowing methodological triangulation. Data analysis indicated that older adults were generally more aware of their energy use pre-SEM and practiced energy saving behaviours learnt from upbringing. This appeared to result in negligible positive benefits and low engagement with the device. Other limiting factors included lack of technical skills and confidence, and the risk of losing the comfort and convenience of using electrical appliances. The device also triggered negative emotions and depression amongst some older adults surrounding electricity usage, potentially leading to dangerously cold homes. Consequently, the scheme's appropriateness is questioned, especially for older adults, and improvements are suggested for SEMs and the scheme.

Keywords: Smart Energy Monitors, Older adults, Awareness, Behaviour 


\section{Introduction}

Anthropogenic climate change is a major threat currently facing humanity. In 2015 , buildings were responsible for approximately $40 \%$ of global energy use with $29 \%$ of all carbon emissions being produced from domestic housing within the UK (Ahmad et al., 2016; Foster et al., 2010). Electricity usage has increased by $39 \%$ from households since 1990 primarily due to population growth, consumer culture and a rise in living standards despite enhanced efficiency of electronic appliances (EEA, 2015; DECC 2013a). Reduction of residential energy use is therefore of key importance in limiting our contribution to global warming and helping to achieve the $20 \%$ reduction in energy consumption required by the UK's energy strategy to meet security of supply objectives (Smart Energy GB, 2016; DECC, 2013b).

A problem with electricity at present is that it is an abstract force entering a household through hidden wires. This makes it 'invisible', both physically and cognitively, with most consumption occurring unreflectively. This can lead to people being disassociated from and unaware of their electricity use (Hargreaves, 2010). Darby (2010) further points out that British people have low understanding of their energy bills and what drives them.

A proposed solution to these problems are Smart Energy Monitors (SEMs). These monitors provide a digital display interface showing feedback relating to how much electricity a home is consuming in near-real-time, giving a more transparent representation of electricity usage than a static bill (Faruqui et al., 2010). Old gas and electricity meters across the UK show cumulative consumption, but are often positioned in inaccessible places, resulting in them getting checked rarely (Smart Energy GB, 2016). However, as the SEM display unit is mobile, it can be put anywhere in the home making it more accessible and 'visible' showing household members how much electricity they are using in either monetary values (f), carbon dioxide $\left(\mathrm{Kg} \mathrm{CO}_{2}\right)$ or kilowatt hours ( $\mathrm{kWh}$ ). This could potentially motivate users to learn about their energy habits and increase their 
awareness of energy use, which in turn might prompt people to make rational (i.e. better informed) decisions to cut their consumption via adopting energy saving measures to lower their energy bills and carbon footprint (Hargreaves et al., 2012; Buchanan et al., 2014; Wallenborn et al., 2011). This is one of the reasons behind the UK government's $f 11$ billion roll-out scheme to offer SEMs to every UK household by 2020 (DECC, 2009). This scheme has now been taken over by the Department for Business, Energy and Industrial Strategy.

Although these SEMs appear to be a revolutionary energy saving technology, this 'one-size-fits-all' policy may not benefit all users (Van Dam et al., 2010; Greenberg \& Huang, 2009). A traditionally excluded group in the design and use of Information and Communication Technologies (ICT) are older adults (as those aged 60 years or older, World Health Organisation, 2013), leading to an age-based 'digital divide' (Neves \& Amaro, 2012). Research has shown that older adults are less likely to use or be willing to use technology than younger people (Eisma et al., 2004; Mitzner et al., 2010; Hanson, 2010). Marquie et al. (2002) also reported older adults' negative self-efficacy as being 'too old for technology' with some experiencing fear and anxiety when trying to learn how to use a computer. These problems amongst others could potentially hinder the promised benefits and effectiveness of SEMs as a motivator to reduce the energy use of older adult users. It is also a significant issue for the roll-out scheme considering that older adults make up around $17.7 \%$ of the UK population and outnumbering those under 16 for the first time in the 2001 census (Office for National Statistics, 2016). On average, older adults also spend longer time periods in their homes and the need for warmer homes increases with age, hence older adults consume relatively more energy (Eisma et al., 2004). Some may also be fuel rationing with fuel poverty tending to increase with age (Barnicoat \& Danson, 2015). Older adults are therefore an important group to study and should be carefully considered in the design, development and deployment of energy saving technologies and policy.

Despite this, the literature at present is lacking detailed research focussing on older adults as end users, especially towards assessing their awareness of and behavioural responses to the feedback provided to them by SEMs. This study aims to address that gap and assess whether SEMs are an appropriate technology for older adults. In order to achieve this overarching aim, the following objectives were established: 
1) Explore how introduction of SEMs affects the awareness of energy use and the behaviour of older adults compared to younger-middle aged adults.

2) Explore factors that may restrict the positive impact of SEMs on these groups, and propose potential ways to improve the SEMs for both age groups, but especially older adults.

\section{$2 \quad$ Literature review}

A wide range of literature has started to focus on potential ways to motivate residential end-users to better manage and reduce their energy consumption. Ideas have included displaying energy labels on electrical appliances (Boardman, 2004), providing in depth energy advice via websites, through leaflets or face-to-face (Abrahamse et al., 2007), providing more informative bills (Wilhite \& Ling, 1995), and most recently by displaying electricity use feedback via SEMs. The latter idea can be related to a theoretical model produced by Fischer (2008) which predicts that energy use tends to fall when people know it is being monitored.

For this study, feedback is defined as the provision of information about the amount of energy a household uses over a given period of time (Buchanan et al., 2014). At present, the majority of energy feedback is provided as an energy bill. This form of feedback results in households gaining information about their energy consumption sometime after consumption (Grønhøj \& Thøgersen, 2011). However, non-continuous feedback has been shown to have weak effects on lowering energy consumption (Abrahamse et al., 2005; Nilsson et al., 2014). It also makes it harder for people to link specific actions entailing energy use (such as boiling the kettle) to their impact on their energy bill. Hence, SEM feedback showing real-time consumption costs may help (Chiang et al., 2014; Foster et al., 2010).

Moreover, the effect of real-time feedback from SEMs might be expected to follow the information deficit model' (Wilhite \& Ling, 1995), which states that consumers lack information about their consumption but feedback provision gives them increased awareness of their energy use and allows them to learn through experimentation about reductions opportunities (Darby, 2006). However, feedback only works if people 
respond to it appropriately (Strengers, 2011). This is important because energy reduction will not happen by simply having an SEM installed. Rather, individuals need to respond to the feedback, make sense of measurement units, work out whether they are efficient or not and then act as micro-resource managers by balancing the benefits and costs of resource use (Strengers, 2011; Hargreaves, 2012). Although, Petkov et al. (2011) argue that this could lead to cognitive overload and may not help users transition to more sustainable and efficient habits.

Furthermore, drawing on social practice theory, Shove (2003) argues that acts of energy consumption or 'practices' such as washing clothes or cooking occur automatically with little thought and attention. This is due to them being culturally acquired and deeply engrained into daily habits and routines (Shove, 2010). People do not seek to consume energy as such; rather, energy consumption occurs indirectly due to everyday essential activities (Froehlich et al., 2010; Shove, 2010; Shove \& Walker, 2014). This raises questions about whether the feedback information provided will be seen by users as relevant and of interest, and whether the feedback from SEMs can help shift existing habits. If feedback from SEMs does work, it would be through encouraging reflection on existing practices, and encouraging change. It has been suggested that sustainable behaviours and habits could potentially be embedded within practices over time (Warde, 2005; GramHanssen, 2011).

Recent SEM studies have produced some interesting positive results. SEMs have been linked to an increase in the uptake of energy saving behaviours (Hargreaves et al., 2010 \& 2012; Buchanan et al., 2014). These included switching off lights when not in use, not leaving appliances on standby, boiling less water in the kettle and turning down the temperature of a washing machine load amongst others. SEMs have also been shown to increase investigative behaviours around the home identifying particularly energy inefficient and wasteful appliances, influencing people to either use them less or replace them. These behaviours that have been influenced by the SEM could have a combined positive effect of lowering household energy consumption from anywhere between 5-20\%, with the added knock on benefit of saving money on consumer energy bills and reducing carbon emissions (Darby, 2006; Fischer, 2008; Van Dam et al., 2010; Abrahamse et al., 2005). 
Despite an array of positive SEM effects being stated and observed, some negative effects have also been detected. These negative effects included evidence of a 'novelty factor', where, after a certain time, participants either lose enthusiasm or interest in the device and/or feel they cannot reduce their energy saving behaviours any further (Hargreaves et al., 2012; Buchanan et al., 2014; Van Dam et al., 2010). The latter is thought to occur for example when energy saving actions start to compromise comfort, convenience and cleanliness of the home with these actions starting to become undesirable in some people's cases (Shove, 2003). Household routines may in fact be impossible to significantly change where various 'necessity' appliances such as kettles, tumble dryers and fridges will always be needed for some. Both these negative effects will be further assessed in this study (Shove \& Walker, 2014).

Not all users may benefit from SEMs and those included in studies of SEMs matters for the results. Most studies, e.g. Hargreaves et al. (2012) and Buchanan et al. (2014), have only focussed on end users who have actively sought out and bought their own SEMs limiting their findings to specific often rather enthusiastic end users who are pre-motivated to want to try and reduce their energy use or have a certain interest in energy issues. SEMs may only appeal to people with certain traits, e.g. those who are more environmentally conscious or financially motivated to reduce consumption (Wallenborn et al., 2011; Murtagh et al., 2014). As a result, it could be argued that the positive findings from these existing studies are unlikely to be generalisable to the wider UK population, who may or may not be less enthusiastic about SEMs by comparison, and hence are possibly overstating the potential energy reduction benefits (5-20\%) that SEMs could bring. This study will therefore instead focus on end users that have never been given an SEM before, loaning one for free as part of this study. This will better mimic the government's free roll-out scheme with interview and diary responses likely to be more representative of the general population who have not actively sought to buy an SEM previously.

There are multiple reasons to think that older adults may be less actively engaged with SEMs. Older adults are less likely to adapt their normal day-to-day behaviours (Davis, 2002; Mills \& Schleich, 2012). Moreover, willingness to pay for environmental protection declines with age, possibly due to perceived shorter remaining 
lifetimes, hence lower expected return benefits from this preservation (Carlsson \& Johansson-Stenman, 2000). There also seems to be a tendency towards older adults being afraid, unwilling and unable to use some technologies (Mitzner et al., 2010) with lower levels of technology adoption compared to younger adults (Mills \& Schleich, 2012). It is thought that this is primarily due to lack of digital literacy, technological skills and problems of accessibility and usability amongst other factors, with older adults often not growing up with such technologies (Neves and Amaro, 2012; Barnicoat \& Danson, 2015). The Office for National Statistics (2014) shows that both internet-based activities and use of mobile ICT technologies decreases with age. In contrast, Neves \& Amaro (2012) show a slow rise in the increased use of ICT among older adults, with increasing numbers thinking they are not a technophobe or too old for technology. In addition, Hanson (2010) shows that older adults are more likely to put effort in learning to use a technology if they are interested in it or it is perceived as filling a need in their lives. Nevertheless, there is ground for concern that older adults may not be able to engage with new technologies (like SEMs) and will be disadvantaged and left behind in contemporary society (Selwyn, 2004). This study will therefore focus on older adult users, in comparison with young and middle age adults.

To conclude, there is a need for more research to understand the responses of older adults in terms of changed awareness and behaviour to the SEMs, in order to better assess whether it is appropriate for them or potentially needs improving by both the government and energy providers. This knowledge will be important in realising whether SEMs can help enable all age groups to move towards a more sustainable, low carbon future.

\section{$3 \quad$ Methodology}

Since little is known about the responses of older adults to SEMs, a relatively open-ended, exploratory approach was chosen. To gain some understanding of the full, rich experience users had with the SEMs a qualitative, interpretative method was deemed appropriate. Data collection using semi-structured diaries and 
interviews allowed exploration of the pre-identified themes of awareness and behaviour, whilst allowing further themes to emerge.

To be able to see if older adults' responses to SEMs are distinct from those of younger to middle aged users, comparison between the two age groups was included. The research was also designed to be comparative in a second respect, studying the effects on participants with no prior experience of SEMs. Participants were therefore provided with SEMs for a month, and prompted to report their experiences, allowing comparison of awareness and behaviour both before and after the introduction of the monitors.

\subsection{Data collection}

\subsubsection{Recruiting participants}

Participants for the study were sampled purposively as this allows the researcher to select the most productive participants to answer the research questions (Marshall, 1996). In this study, the kind of participants recruited were those who paid for the energy bill, who fell within a certain age range (aged 25-59) or (aged 60+) and who had never used a SEM before so that all participants had the same level of SEM exposure. This method also allowed inclusion of those who may be less interested in SEMs prior to the study as opposed to previous studies whereby the majority of participants had a prior interest in SEMs (Hargreaves et al., 2012; Buchanan et al., 2014; Barnicoat \& Danson, 2015). Family, neighbours and friends of the researcher, sometimes referred to as 'interviewing of acquaintances' (Blichfeldt \& Heldbjerg, 2011), who fitted these criteria were then selected for the study. This was because rapport with these participants had already been built, drawing on the trust and openness advantages that these interpersonal relationships can bring to the research (Stebbin, 1972). In addition, previous knowledge of the participants helps to complete a fuller portrait of their background when analysing responses as well as facilitating longer, in-depth interviews around the SEM subject matter (Blichfeldt \& Heldbjerg, 2011). 
The study covered 20 households, with a total of 58 inhabitants. Of these households, 9 were made up of 15 older adult participants (defined as aged 60+, in practice 63-82), and the remaining 11 households were made up of 21 younger-middle aged adults (defined as aged 25-59, in practice 34-52) and their children. A total of 26 participants from the 20 households participated in the study, through writing a diary and/or as interviewees (see Table 1). This was deemed an appropriate sample size because unlike quantitative studies, qualitative studies aim for a better understanding of how participants experience and make sense of their own lives, rather than be representative of populations (Valentine, 1997).

\begin{tabular}{|l|l|l|l|}
\hline & $\begin{array}{l}\text { Number of active } \\
\text { participants in age } \\
\text { and sex group }\end{array}$ & Diary & Interview \\
\hline Older Males (OM) (Aged 60+) & 6 & 3 & 6 \\
\hline Older Females (OF) (Aged 60+) & 6 & 6 & 5 \\
\hline Younger Males (YM) (Aged 25-59) & 9 & 6 & 6 \\
\hline Younger Females (YF) (Aged 25-59 & 5 & 5 & 3 \\
\hline Total & $\mathbf{2 6}$ & $\mathbf{2 0}$ & $\mathbf{2 0}$ \\
\hline
\end{tabular}

$\underline{\text { Table.1 }}$ - Types of data collected, per participant age and sex. 


\subsubsection{Preparing the SEMs}

Twenty GEO Smart Energy Monitors were obtained from Cumbria Action for Sustainability. These monitors had various features available for participants to use (Fig.1 and Box 1).

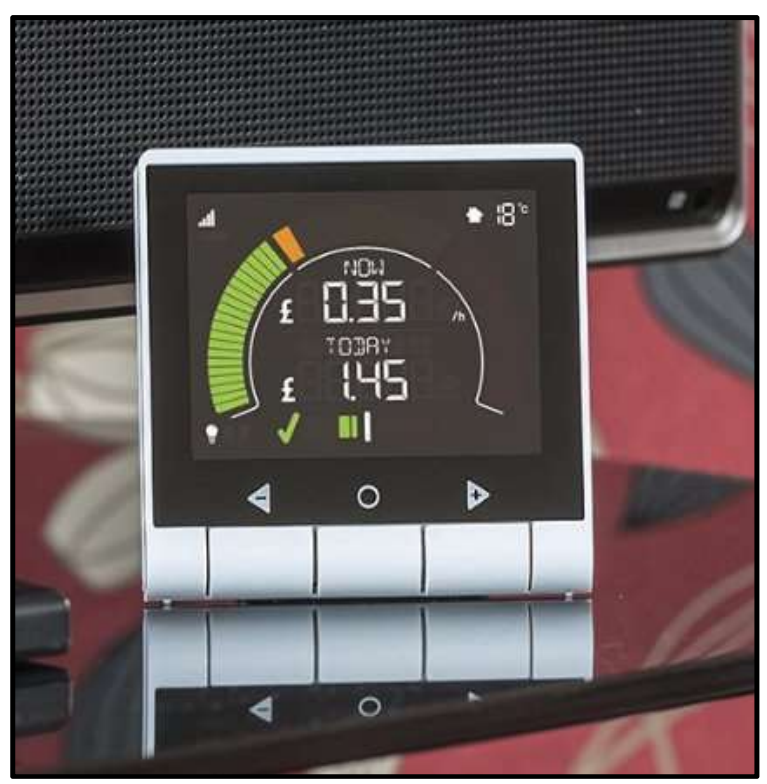

Fig.1 - GEO Minim Smart Energy Monitor used in the study.

- Shows real-time electricity usage in either $\mathrm{f}, \mathrm{kWh}$ or $\mathrm{kg} \mathrm{CO}_{2}$ per hour - using current tariff.

- Shows historic consumption (total electricity usage from today, yesterday, this week, last week, this month, last month).

- Budget bar enables a daily budget of energy use to be set - indicates with a tick or cross symbol whether this is being met or not.

- Speedometer to show real-time current electricity use (GEO, 2015).

Box 1 GEO SEM summary features.

Before the study, a SEM was installed and trialled in the researcher's own home for a month. Although no data was recorded, this sensitised the researcher to the topic and allowed them to become immersed in the study 
experience from the position of a participant enabling better insight and interpretation of the experience of the participants (Pace, 2012). The interview questions were also designed factoring this pre-trial experience in and it further helped build rapport with the participants.

The Smart Energy Monitors were then installed into the 20 participating households where a short briefing and an information sheet were given about what the study involved.

\subsubsection{Diaries}

Diaries were used to allow participants to report their responses to the SEMs throughout the month-long study (early October to early November 2016). Each household was required to nominate a person to write the study diary with blank diaries being provided by the first author. Clear instructions of what they could include in their entries were given in an information sheet. This produced a total of 20 diaries; nine (aged 60+) and eleven (aged 25-59) (cf. Table.1).

The diaries were completed as and when the participant wanted to in their free time giving freedom to write whenever convenient, and when they felt it was relevant. This reduced the risk of forgetting important experiences when it came to the post-study interview (Alaszewski, 2006). The only restriction placed upon participants was to complete seven diary entries in total on different days of the study. This logging of experiences over time enabled study of how awareness of and behaviour towards the SEM changed with time, comparing earlier entries with subsequent ones (Elliott, 1997). However, some entries were missing where participants had simply forgotten to write them.

Diaries run the risk of some accounts being 'sanitised', perhaps omitting experiences that they think are unacceptable or too trivial to include (Bytheway \& Johnson, 2002; Alaszewski, 2006). Therefore, these findings were complemented with interviews to fill these potential missing information gaps and provide an extra layer of depth to responses. 


\subsubsection{Semi-structured interviews}

After the month-long study, participants from 16 of the households agreed to take part in an interview. The participants from the remaining 4 households could not participate due to a range of reasons, including illness or being away on holiday. In a few cases more than one person was interviewed per household. A total of 20 people were interviewed, including 11 older adults (aged 60+) and 9 younger-middle aged adults (aged 25-59) (cf. Table.1).

The choice of location and time for the interview was given to the participant and all opted to have this at their home in the town of Frome (UK). This choice allowed them to feel more relaxed and comfortable in the less pressurised environment of their own home, thus increased the probability of more accurate and natural responses (Crawford, 1997). These interviews were digitally recorded using a dictaphone and later transcribed and coded.

Post-study semi-structured interviews complemented diary responses and allowed exploration of complex behaviours and awareness, as well as permitting open responses from participants in their own words (Longhurst, 2003). Like diaries, they enabled participants to have freedom in expressing their own unique ideas allowing new avenues of discussion and themes to unfold not previously considered by the researcher (Valentine, 1997; Phillips \& Johns, 2012).

Interview questions were devised based on the pre-trial experience the researcher had with the SEM and a review of the literature. Questions aimed to address the two main objectives of the study. The focus was primarily on whether awareness of energy use, behaviour and engagement had changed since having the SEM installed. This was followed by participant opinions on the pros and cons of SEMs and suggestions for roll-out improvement. Some of the main questions asked are provided in Box 2 . 
Do you think the information you received from the Smart Energy Monitor display increased your awareness of how much energy you use in the house or were you aware of how much energy you were using before the study?

Has your (or other household members) behaviour or daily routine changed in an effort to reduce energy use as a result of the Smart Energy Monitor being in the home?

Would you say your engagement and interest with the monitor increased, decreased or stayed the same throughout the study? (Prompt: Why was this?)

Was there anything you liked / did not like about the monitor or having the monitor installed in your home?

In your opinion is the Smart Energy Monitor a useable and useful technology for people in your age group ((25-59) /(60+))? (Prompt: why/why not?)

Can you suggest any ways to improve the monitor? Is there anything else you can suggest to improve the roll out scheme?

Box 2 Selected interview questions.

The semi structured script design also allowed the ordering of questions to be flexible to the varying responses given by participants. Prompts and additional questions were asked when appropriate to delve deeper where a response was sometimes lacking detail. These prompts also helped guide participants if they drifted off track from the focus of the question. Interviews were conducted face-to-face rather than over the telephone as although this is more time consuming, a better rapport was built with the interviewees, hence they were more likely to be forthcoming with their responses (Coleman et al., 2013).

\subsection{Data analysis approach}

To make sense of the data, both diaries and interviews were first transcribed. These were then coded using thematic analysis as it does not assume a specific theoretical perspective (Murtagh et al., 2014). The technique first involved getting familiar with the data, reading through transcripts multiple times and making comparisons between and within the different age groups responses (Braun \& Clarke, 2006; Longhurst, 2003). 
Sections of text from the transcripts were then highlighted and labelled with a descriptive code based on the research objectives or on whether they seemed important, were repeated, surprised the researcher, or related to concepts within the literature (Braun \& Clarke, 2006; Bazeley, 2013). This technique allowed a number of bottom-up inductive themes to emerge, as well as top down deductive themes derived from the research objectives and literature (Saldaña and Saldana, 2009). This process was then repeated and re-coded in light of a deeper understanding of the material from the first cycle.

The resulting descriptive codes were then further analysed and reviewed away from the main body of text and given an interpretative analytical $\operatorname{code}^{1}$ that represented the wider themes and patterns emerging from the dataset (Braun \& Clarke, 2006). The analytical themes from the coding tables were then further crossexamined and verified across the participant groups. Where an analytic theme recurred and was common for more than two participants it was deemed significant due to the fairly small sample size (Saldaña and Saldana, 2009). These themes were compared between age groups.

Finally, the analysis presented here is based on a selection of analytical themes that fit Wilhite and Ling's (1995) information deficit model, but also ones that indicated - potentially important or surprising - further mediating factors not captured by that model. The analysis was performed by the first author, apart from the final step which was done jointly.

\subsection{Ethics}

Once the information sheet was read and understood and participants agreed to take part in the study, a consent form was signed. This explained the anonymity of their responses and what they would be used for as well as the right to withdraw at any stage throughout the study. Participants were reminded of these rights at different stages throughout the research to maintain integrity (Miller \& Bell 2002).

\footnotetext{
${ }^{1}$ The analytical codes, and further supporting material pertaining to the methods used, can be found in this online repository: https://dx.doi.org/10.17635/lancaster/researchdata/277
} 
When analysing and writing up the research, to protect the identity of the participants, names were replaced with codes (Longhurst, 2003). This was given in the following format:

1) $\mathrm{O}=$ Older participant aged $60+, \mathrm{Y}=$ Younger participant aged $25-59$

2) $M=$ Male, $Y=$ Female

3) Participant number within that particular age and sex group.

For example, the code YM9 means the Younger Male participant number 9.

\section{$4 \quad$ Results and Discussion}

In the first part of the analysis, we follow Wilhite and Ling's (1995) information deficit model, and present a contrast of the participants' awareness and behaviour before and after the introduction of the SEM. The analysis shows a limited effect for both age groups albeit for different reasons. In the second part, the analysis will be expanded to a range of further mediating factors that help explain the limited impact of the SEMs. The impact of these mediating factors also differ markedly between older and younger adults. For both parts the key themes that emerged are presented and discussed in separate sub-sections.

\subsection{Before and after: effects on awareness and behaviour}

\subsubsection{Pre-SEM energy awareness and behaviour}

The majority of older adult participants mentioned that they were already aware of energy use and were already practicing energy saving behaviours learnt from their upbringing before having the SEMs. This was influenced by their parents' energy behaviours and efficiency measures, and passed on through their upbringing: 
"I don't use that much water in the kettle...and this is very much my generation and my mother's generation...you never use the oven for one thing...if you are going to turn your oven on you bake a batch of scones or some flapjacks or something..."- (OF4) Interview.

"Another of my energy saving behaviours that I did before is that I only put my dishwasher on when completely full as its only two people living in this house. I was ironing my last few pieces of clothing and I turned the electric off and managed to iron quite a few pieces of clothing with the last heat in the iron. But then I have been doing this for years and years - that is why we have a low electric bill" -(OF1) Diary entry.

"I mean people like me used to go around the house and pull out every plug at night because power was very expensive at one time and equipment was very inefficient..." - (OM4) Interview.

This result regarding older adults stands in contrast to the (25-59) age group who mostly admitted to being far less aware and conscious about their energy consumption and its associated costs before using the SEM:

"I didn't really pay attention to leaving lights on and that sort of thing...I would just travel around the house...you know I did what I wanted (laughs)" - (YF2) Interview.

"To be honest before the meter was installed I had no idea of how much electricity I was using and how much I was paying for it. The meter has already made me much more aware of electricity costs"

-(YM2) Diary entry.

“...my daughter is totally careless on her energy usage...you know there would probably be no one there at lunchtime and you'd walk in and the heat would hit you... you know I switch my standby lights off at night...and I told my granddaughter to switch it off and she said 'don't be silly because it costs nothing to have those on'..." - (OM4) Interview.

In addition, many older adults had the opinion that the younger generation are far less aware and more careless with energy use compared with them. This is in line with previous research showing older adults claiming significant differences across generations (Anderson et al. 2012). 
Hence, studying pre-SEM awareness of energy use and costs, we may tentatively suggest that SEMs would be more beneficial and appropriate for the younger adult generation. Older adults may have less need for prompts to become aware of the energy they use and its costs.

\subsubsection{Awareness of energy use and cost}

Almost all younger-middle aged participants commented positively on how the SEM had increased both their awareness of household energy use and its associated cost:

"I think it's a very good tool to raise awareness and keep tabs on how much energy you're using and how much it is costing you" - (YM2) Interview.

"The main energy users are the washing machine and tumble dryer, which is a pain as we are a family of four so have a lot of washing most days, I did notice the dishwasher didn't use much more energy which was a surprise, but I was surprised to see how much energy is used to boil a kettle" -

\section{(YM7) Diary entry.}

As a result, this caused them to monitor energy usage around the home more frequently than before the study. These findings are similar to those of previous studies that found more frequent monitoring (Hargreaves et al. 2010, 2012) due to the SEM increasing conscious visibility (Buchanan et al., 2014). In addition, some younger-middle aged participants also mentioned the positive knock-on effect the SEM had in increasing awareness of reducing other household resources:

"I've been more aware of how much gas and water l've been using as well...so like my wife's terrible at leaving dripping taps and stuff like that...so l've been on the ball kind of watching that as well..." -

(YM4) Interview.

All this evidence supports the first part of Wilhite \& Ling's (1995) information deficit model, stating that information provision improves consumers' awareness of their consumption of resources. 
In contrast, for many older adults the SEM only enhanced their awareness minimally. This was because of their previous awareness of energy use and growing up with energy saving behaviours. This result further supports the argument that SEMs are less useful and appropriate for older adults.

\subsubsection{Investigative behaviours}

Both participant groups mentioned how the SEM prompted them to think about taking actions to change their energy behaviours and habits:

"Just spotted oven was costing 33p per hour - quite surprised and might make you think how often you make hot food?" - (YM4) Diary entry.

In addition, almost all younger-middle aged adults showed evidence of acquiring investigative behaviours surrounding their energy use, using the SEM to identify high usage and costly appliances. They also used it to compare the efficiency of different appliances. The SEM can be seen as a learning tool (Darby, 2006) allowing users to teach themselves about electricity usage by experimentation:

"...our sort of baseline is $2 p$ with fridges and freezers always on...but anything above that it was sort of like a game to get it back down to near the baseline..."-(YM3) Interview.

"The gadget seemed quite a novelty tonight - I played around turning lights on and off, trying to work out what was costing the $4 p$ per hour." - (YM4) Diary entry.

"It would be interesting to know how the gas consumption of heating water equates to heating the same amount of water in the kettle, which seems to take the meter up to $38 p$ per minute, similarly the microwave - using that compared with heating on the gas stove - how relatively efficient and price economic are they?" - (YF4) Diary entry.

In contrast, these investigative behaviours and new habits were far less common in the older adult group who generally thought they knew and were behaving in a good way already. Again, this raises questions about how 
successful SEMs are likely to be for this age group in terms of their ability to influence energy behavioural change.

\subsubsection{Behaviours entailing energy use}

Overall, both participant age groups did very little to act upon the feedback being provided to them by the SEM, changing only minor aspects of their behaviour to reduce energy consumption.

The minimal energy saving behaviours that did occur were few and far between and with participants rarely changing their behaviour in more than one area. As mentioned, older adults were generally already largely partaking in these energy saving behaviours prior to having the monitor installed but some did suggest some areas they could improve.

It was mainly the younger adults that changed their behaviour at all. And for many of them, the effect of the SEM wore off after some time:

"At the beginning I was really checking it all the time and writing it down and the last week or so I just forgot about it... think now it's almost just become part of the furniture..." - (YF1) Interview. "Haven't looked at monitor for days now so think the novelty has worn off!" - (YM4) Diary entry. "I notice that I am becoming a bit immune to the meter now that we have had a few weeks of it. I wonder whether this is a common problem?" - (YF4) Diary entry.

This tended to be as a result of quickly learning about their household energy use, meaning the SEM eventually no longer provided them with any new information and hence the device became backgrounded as its novelty wore off. For the younger-middle aged adult group this tended to occur after 1-2 weeks, much quicker than what was found in some of the longer studies (e.g. Hargreaves et al., 2012; Van Dam et al., 2010).

Despite this novelty decay effect, participants said they would use the SEM again if they bought a new appliance to see how much it used or if it gave them new information or reminders: 
"I think it was because I knew everything then...nothing was going to change...there was no new appliance...so no new information... and I kind of knew what was costing what now and that was it...so yeah I think you need more information or something to keep you interested" - (YM4)

\section{Interview.}

"Once you are aware of what appliances use what... it does decrease after that ...but if I had a new device come in or something...you know like a new dishwasher or something then I would have checked" - (OM6) Interview.

"...the monitor could say 'Did you know that by only filling up your kettle with enough water to have for your cup of tea...you could save on average $£ 50$ a year'...that sort of thing...and people would go 'great I'll save $f 50$ '...so it's giving you those little tips and incentives..." - (YM5) Interview.

Fischer (2008) suggests that the success of feedback depends on its content, but also duration and frequency. These results provide evidence that people's engagement could be sustained if new information was given to them regularly over time. This could be achieved by educating people with a new energy saving tip to try periodically either through the SEM display screen or perhaps through a notification in an app, email or through the post. This suggested improvement could further help with the problem observed by Hamza \& Gilroy (2011) who noted dissatisfaction in SEMs supplying sufficient information in areas where potential savings could be made.

Overall, these findings support the quantitative studies (Darby, 2006; Faruqui et al., 2010) that suggest only limited consumption reduction from using SEMs of around 3-13\%. And in line with such earlier studies, our findings raise questions about how successful the roll-out scheme is going to be in substantially reducing energy consumption. We would further suggest that the success will be limited for both the age groups studied here, albeit for partly different reasons.

\subsection{Mediating factors}


This far, our analysis has been closely aligned with Wilhite \& Ling's (1995) information deficit model. The main factors limiting the SEM feedback effect identified have been 1) the pre-existing awareness about energy use among older adults meaning little new information is provided to them by the SEMs, and 2) the novelty effect among the younger adults showing that the amount of new information provided by the SEMs is limited and therefore the effect it has is exhausted over time. That is, as the model predicts, if and as long as there is new information available, people can be expected to make rational decisions and change their behaviour and energy use accordingly.

In line with previous studies (Buchannan et al. 2015; Strengers 2011), we have however also found evidence of mediating factors that mean people react in more complicated fashions to new information. These factors are markedly different for older participants compared to younger adults.

\subsubsection{Comfort and convenience}

A major barrier limiting the success of SEMs for both age groups will be how the comfort and convenience of using some electrical appliances takes priority over the desire to conserve energy. There appeared to be a threshold of minimal energy use that both groups were unwilling to go below. Below this line, where comfort, convenience and cleanliness looked like being compromised, then there was a sense amongst participants that their usage could not or should not be reduced any further (c.f. Shove, 2003). This baseline varied significantly between households and age groups depending on what they considered to be necessities or latent uses of energy:

"I can't give up my strong cup of coffee in the morning either...you know there is a certain line of certain things I'm prepared to pay for..."- (OM6) Interview.

"Yeah definitely...I mean hair dryers, kettles, that sort of stuff we're always going to need" - (YM1)

\section{Interview.}

Moreover, this problem was especially prominent in older adult households where comfort was paramount: 
"I have the TV on all the time I am home, this is my company as I live on my own, so that will not change no matter how much electricity it uses. Some things will change, some will not." - (OF3)

\section{Diary entry.}

"To be honest I would find it very difficult to use less than I am using...the only luxury I allow myself I suppose is I do keep hot water on all the time...but as I say that's because of my age..." - (OF5) Interview.

Older adults may be quite set in fixed routines and habits and as a result less likely to adapt their general dayto-day behaviours (Barnicoat \& Danson, 2015; Davis, 2002). This isn't to say that they were unwilling to undertake change as such, but that they saw comfort and convenience as important reasons to stick with their existing habits. This issue could potentially limit the SEMs' influence on altering energy behaviours.

Non-negotiable appliances that all participants agreed were essential for normal everyday life included the oven, kettle, washing machine, fridges and freezers. Although they acknowledged that these were high usage appliances, they believed they could not do anything differently surrounding their use and the convenience of using them far outweighed the cost (both financially and environmentally) of not using them:

"I'm not someone I think who uses them for fun, so I need them for what I need to use them for...so it was kind of irrelevant because I couldn't make any cut backs I would say I needed to do..." - (YF2)

Interview.

"A problem has arisen. Ok, we can now see that: switching on the dishwasher, washing machine, microwave or any other appliance immediately results in a big swing in the speedometer. But what can we do about it? Stop using labour saving equipment?" - (OM4) Diary entry.

This supports Shove's (2003) findings that energy practices are intensely engrained within people's daily lives, with consumers not using energy for its own sake but rather emerging as a by-product of people's everyday activities (Shove, 2010; Shove \& Walker, 2014; Froehlich et al., 2010). 
Overall, comfort is a complex phenomenon, influenced by many things including socially acceptable norms, living standards and practices of western culture (Shove, 2003; Murtagh et al., 2014) where, for example, washing clothes is now rarely done by hand and making hot water involves a gas or electric heating element. This can potentially render energy saving efforts as socially unacceptable, due to essential appliance usage being just a 'normality' of everyday life (Bartiaux, 2008; Strengers, 2008). This suggests that making energy 'visible' alone may not be enough to reduce energy demand as it fails to recognise wider cultural and social influences surrounding household energy use (Shove et al., 1998; Strengers, 2008). Our study reinforces this result, especially for the case of older adults.

\subsubsection{Handling technology}

Results from this study also showed that older adult participants were either interested in the SEM and fairly competent with technology or were not interested and had difficulty in understanding it. The majority fell in the latter sub-group. Many older adult participants struggled with how to use and set up the monitor, often finding it complicated despite having instructions available to them. This is well aligned with findings from previous research (Marquie et al., 2002; Mills \& Schleich, 2012) about older adults' negative experiences with technology. A couple of older adult participants (OM1 and OF1) even rang up the main field researcher during the study for assistance in re-setting up their SEM as they had accidentally unplugged it. In some cases, older adults were also afraid to press buttons on the device in case they put it on a setting that they would not be able to revert back to:

"No, it stayed there...I didn't want to move it...in fact by the time the study finished it had its back facing the wall...because I thought no I can't stand to see it anymore... I didn't really understand it (laughs)...one minute it was up over the red...and then it was doing this thing and that thing and I didn't know what was going on sometimes..." - (OF3) Interview. 
"...but I left it on the pounds anyway because I was frightened to break it as well...I'm not very technical you see (laughs)" - (ОM3) Interview.

This supports findings that some older adults are afraid and unable to use some technologies (Mitzner et al. 2010). As a result, many left the SEM exactly in the position it was set up, barely using it with some even criticising the roll-out scheme. This may counter research suggesting a decline in the number of older adults who thought they were technophobic (Neves \& Amaro, 2012).

Again, these results question whether the roll-out scheme is appropriate for older adults. The results also challenge SEM developers to redesign and tailor SEMs in order for them to be more usable and accessible for older adult users.

\subsubsection{Emotional responses}

A somewhat surprising theme to emerge from the study was the negative emotional responses participants had to the SEM. These negative emotional responses often resulted in participants not wanting to use the SEM anymore, turning the display face away and hence dissociating themselves from it. These findings contradict suggestions that devices prompting an emotional reaction will keep users positively engaged (Buchanan et al. 2014).

There were several reasons for such negative emotional responses. As discussed above, many of the older adults did not fully understand the display of the monitor, and this was understandably also accompanied by negative emotional responses. Subjective loss of control and low perceived ease of use of a technology can result in negative emotions and attitudes towards it (Kranz et al., 2010).

Money worries can exacerbate such feelings of lack of control and agency. Both age groups were particularly focussed on the budget feature, using it to keep track of spending. However, this sometimes became demotivating when someone had set an unachievable daily budget and were always 'in the red' (overspending). This often led to feelings of guilt and depression: 
"Well I'll actually tell you the truth...it got to the point where we actually turned it over so we couldn't see it anymore... I think the amount we estimated that we put as a benchmark was too low so we were always going over our budget quite quickly...so it was quite depressing...so yeah we always kept going over and I think that's why we kept not taking notice of it..."-(YM3) Interview.

In particular, some older adult participants also mentioned how they felt worried about using electricity and heating appliances to stay warm in case they went over budget:

"...my health takes priority in this case...and because of my health I am at home a lot, I'm sitting down a lot and that makes it really difficult to keep warm...you know if I turn the heating down and wrap stuff round me I don't want to be living like that...I've been very inactive this year so I get cold a lot more easily" - (OF5) Interview.

"I would not like the monitor all the time. When I have the main heating on I would be worried how much it was using. Being a pensioner, I need to keep warm." - (OF3) Diary entry.

Furthermore, some in the younger-middle aged group expressed similar concerns on behalf of older adults:

"My elderly mother was always very concerned with high fuel costs. The smart meter red warnings of high use could put off vulnerable people from having their heating on." - (YM2) Diary entry.

Many older adult people worry about their ability to heat their homes. Barnicoat \& Danson (2015) found that approximately $47 \%$ of people over 65 are worried about paying their energy bills in Scotland. Whilst we can't generalise from this study, the prevalence of worry about energy bills suggests that introducing monitors may cause distress for large numbers of older people.

\section{$5 \quad$ Conclusion and policy implications}

This paper has explored the responses of older adult users (in comparison with younger-middle aged ones) to the introduction of SEMs. The main findings are as follows. 
The potential benefits of SEMs can be conceptualised as providing feedback about energy use to users, allowing them to change their behaviour in response. However, many older adult users in this study were already aware of their energy use, having been brought up to be. Introducing SEMs thus had less effect on them than on younger-middle aged adults, in terms of both awareness and prompting investigative behaviours. Moreover, whilst some older adult users did experience raised awareness of the SEMs, there was overall little change to behaviours entailing energy use.

The study further identified age-specific factors that mediate - and limit - the benefits of feedback from SEMs. Many older adults are dependent on their existing practices, entailing use of heating systems and household appliances. Many older adults are also poorly placed to deal with the technical aspects of SEMs, and often chose to disengage from them. The frustrations with the monitors were keenly felt by some of the older adult participants in this study. Most alarmingly, some of the older adult participants were distressed by the introduction of the monitors, as it became a focus for - and exacerbated - worries about not being able to afford the energy they need to sustain themselves.

This paper contributes to an emerging literature on the responses of older adults to smart meters. This paper verifies, through comparative analysis, that there is indeed a difference between older adults and youngermiddle aged adults. Moreover, older adults were here found to be more negative about SEMs, and more assured about their knowledge about energy use, compared to the most directly comparable previous study (Barnicoat and Danson, 2015). This may be because their study, like others in this area, but unlike ours, was limited to older adults that had expressed an interest in SEMs.

Our findings raise serious questions about the government's roll-out scheme, in terms of older adult participants. Therefore, governments should consider whether SEMs are appropriate for older adults in the first place, compared to government spending on well-insulated and draft proof homes for the elderly.

Furthermore, we suggest there may be merit in targeting the SEM roll-out to younger adults with a voluntary opt-in scheme available to older adults who are interested in reducing their energy consumption and confident 
using technology. However, the novelty effect observed here and in related studies (e.g. Buchs et al. 2018) may still undermine long-term impacts of SEMs with this age group as with younger adults.

A voluntary scheme should require installers to provide tailored advice, one-to-one support and tuition to ensure these users understand the monitors' technical aspects and how to use them in terms of setting reasonable budgets and targets. It would also be beneficial to provide simple help sheets, follow-up support visits, and a support line to call if distressed.

To increase the benefits of an installation visit, the installer could also assess the household's scope to increase energy savings such as draft proofing, additional insulation or better tailored heat controls. Advice on timeof-use tariffs with savings potentially being made by this age group who tend to be at home day time during off peak hours may be beneficial.

In addition, SEM developers should adapt SEMs to older adult users. Suggestions include a larger display screen, a talk feature for those with poor sight and easy-to-use controls. Alarms and red colours indicating high usage should be avoided to minimise distress.

\section{$6 \quad$ Acknowledgements}

We would like to thank Cumbria Action for Sustainability for providing the Smart Energy Monitors needed for the study. We would also like to thank all the participants that kindly gave their time and energy to take part in the project.

\section{$\underline{\text { References }}$}

Abrahamse, W., Steg, L., Vlek, C. and Rothengatter, T. (2005) 'A review of intervention studies aimed at household energy conservation', Journal of Environmental Psychology, 25(3), pp. 273-291. 
Abrahamse, W., Steg, L., Vlek, C. and Rothengatter, T. (2007) 'The effect of tailored information, goal setting, and tailored feedback on household energy use, energy-related behaviours, and behavioural antecedents', Journal of Environmental Psychology, 27(4), pp. 265-276.

Ahmad, M.W., Mourshed, M., Mundow, D., Sisinni, M. and Rezgui, Y. (2016) 'Building energy metering and environmental monitoring - A state-of-the-art review and directions for future research', Energy and Buildings, 120, pp. 85-102.

Alaszewski, A.M. (2006) Using diaries for social research. London, United Kingdom: SAGE Publications.

Anderson, W., White, V. and Finney, A. (2012) 'Coping with low incomes and cold homes', Energy Policy, 49, pp. $40-52$.

Barnicoat, G. and Danson, M. (2015) ‘The ageing population and smart metering: A field study of householders' attitudes and behaviours towards energy use in Scotland', Energy Research \& Social Science, 9, pp. 107-115.

Bartiaux, F. (2008) 'Does environmental information overcome practice compartmentalisation and change consumers' behaviours?', Journal of Cleaner Production, 16(11).

Bazeley, P. (2013) Qualitative data analysis: Practical strategies. London: SAGE Publications.

Blichfeldt, B.S. and Heldbjerg, G. (2011) 'Why not? The interviewing of friends and acquaintances' http://vbn.aau.dk/files/165935946/working_paper_sdu.pdf [19/11/16].

Boardman, B. (2004) 'New directions for household energy efficiency: Evidence from the UK', Energy Policy, 32(17), pp. 1921-1933.

Braun, V. and Clarke, V. (2006) 'Using thematic analysis in psychology', Qualitative Research in Psychology, 3(2), pp. 77-101.

Buchanan, K., Russo, R. and Anderson, B. (2014) 'Feeding back about eco-feedback: How do consumers use and respond to energy monitors?', Energy Policy, 73, pp. 138-146. 
Buchanan, K., Russo, R. and Anderson, B. (2015) 'The question of energy reduction: The problem(s) with feedback', Energy Policy, 77, pp. 89-96.

Buchs, M., AbuBakr, S.B., Blunden, L., Bourikas, L., Falkingham, J., James, P., Kamanda, M. and Y. Wu. (2018) 'Promoting low carbon behaviours through personalised information? Long-term evaluation of a carbon calculator interview' Energy Policy 120: 284-293.

Bytheway, B. and Johnson, J. (2002). Doing diary-based research. In: Jamieson, A. and Victor, C.R. (eds). Researching Ageing and Later Life: the Practice of Social Gerontology, Oxford: Blackwells Publishing, pp. $155-74$.

Carlsson, F. and Johansson-Stenman, O. (2000) 'Willingness to pay for improved air quality in Sweden', Applied Economics, 32(6), pp. 661-669.

Chiang, T., Mevlevioglu, G., Natarajan, S., Padget, J. and Walker, I. (2014) 'Inducing [sub]conscious energy behaviour through visually displayed energy information: A case study in unive $3^{3}$ ity $^{8}$ accommodation', Energy and Buildings, 70, pp. 507-515.

Coleman, M.J., Irvine, K.N., Lemon, M. and Shao, L. (2013) ‘Promoting behaviour change through personalized energy feedback in offices', Building Research \& Information, 41(6), pp. 637-651.

Crawford, I. (1997). Chapter 5: Personal Interviews In: Food and Agriculture Organisation of the United Nations. Agriculture and Consumer Protection. FAO. Rome, Italy.

van Dam, S.S., Bakker, C.A. and van Hal, J.D.M. (2010) ‘Home energy monitors: Impact over the mediumterm', Building Research \& Information, 38(5), pp. 458-469.

Darby, S. (2006) The effectiveness of feedback on energy consumption a review for DEFRA of the literature on metering, billing and direct displays. http://www.eci.ox.ac.uk/research/energy/downloads/smartmetering-report.pdf [15/8/16]. 
Darby, S. (2010) 'Smart metering: What potential for householder engagement?', Building Research \& Information, 38(5), pp. 442-457.

Davis, G. (2002) 'An exploratory analysis of residential electricity conservation survey and billing data: Southern California Edison, summer 2001'. http://www.energy.ca.gov/reports/2002-05-20_400-02006F.PDF $[2 / 11 / 16]$.

DECC (2009). Smarter Grids: The Opportunity, Department of Energy and Climate Change, London.

DECC (2013a) Energy consumption in the UK. https://www.gov.uk/government/collections/energyconsumption-in-the-uk [19/10/16].

DECC (2013b) Energy Efficiency Strategy 2013. https://www.gov. uk/government/uploads/system/uploads/attachment_data/file/266187/ 2901415_EnergyEfficiencyStrategy_acc.pdf [23/10/16]

Eisma, R., Dickinson, A., Goodman, J., Syme, A., Tiwari, L. and Newell, A.F. (2004) 'Early user involvement in the development of information technology-related products for older people', Universal Access in the Information Society, 3(2), pp. 131-140.

Elliott, M.H. (1997) 'The use of diaries in sociological research on health experience', Sociological Research Online, 2(2).

European Environment Agency (EEA) (2015) Final energy consumption by sector. http://www.eea.europa.eu/data-and-maps/indicators/final-energy-consumption-by-sector-5 $[28 / 8 / 16]$.

Faruqui, A., Sergici, S. and Sharif, A. (2010) 'The impact of informational feedback on energy consumption-A survey of the experimental evidence', Energy, 35(4), pp. 1598-1608.

Fischer, C. (2008) 'Feedback on household electricity consumption: A tool for saving energy?', Energy Efficiency, 1(1), pp. 79-104. 
Foster, D. , Lawson, S., Blythe, M., Cairns, P. (2010) 'Wattsup?: motivating reductions in domestic energy consumption using social networks', Proceedings of the 6th Nordic Conference on Human-Computer Interaction: Extending Boundaries, October 16-20, 2010, Reykjavik, Iceland.

Froehlich, J., Findlater, L. and Landay , J. (2010) 'The design of eco-feedback technology'. In Proceedings of the SIGCHI Conference on Human Factors in Computing Systems. ACM pp.1999-2008.

GEO (2015) Minim energy monitor / green energy options (geo). http://www.geotogether.com/products/energy-monitoring/minim/ [22/8/16].

Gram-Hanssen, K. (2011) 'Understanding change and continuity in residential energy consumption', Journal of Consumer Culture, 11(1), pp. 61-78.

Grønhøj, A. and Thøgersen, J. (2011) 'Feedback on household electricity consumption: Learning and social influence processes', International Journal of Consumer Studies, 35(2), pp. 138-145.

Hamza, N. and Gilroy, R. (2011) 'The challenge to UK energy policy: An ageing population perspective on energy saving measures and consumption', Energy Policy, 39(2), pp. 782-789.

Hanson, V.L. (2010) 'Influencing technology adoption by older adults', Interacting with Computers, 22(6), pp. 502-509.

Hargreaves, T., Nye, M. and Burgess, J. (2010) 'Making energy visible: A qualitative field study of how householders interact with feedback from smart energy monitors', Energy Policy, 38(10), pp. 61116119.

Hargreaves, T., Nye, M. and Burgess, J. (2012) 'Keeping energy visible? Exploring how householders interact with feedback from smart energy monitors in the longer term', Energy Policy, 52, pp. 126-134.

He, H. A., Greenberg, S. and Huang, E. M. (2009) ‘One size does not fit all: Applying the Transtheoretical Model to Energy Feedback Technology Design'. Department of Computer Science, University of Calgary, Calgary, Alberta, Canada, 2009. 
Kranz, J., Gallenkamp, J., Picot, A.O. (2010). Exploring the role of control-smart meter acceptance of residential consumers. In: Proceedings of the 16th American Conference on Information Systems (AMCIS) Lima, (August 12-15, 2010), pp. 1-9.

Longhurst, R. (2003). Chapter 8: Semi-structured Interviews and Focus Groups. In: Clifford, N. and Valentine, G. Key Methods in Geography. Sage: London. Pp 117-132.

Marquié, J.C., Jourdan-Boddaert, L. and Huet, N. (2002) ‘Do older adults underestimate their actual computer knowledge?', Behaviour \& Information Technology, 21(4), pp. 273-280.

Marshall, M.N. (1996) 'Sampling for qualitative research', Family Practice, 13(6), pp. 522-526.

Mills, B. and Schleich, J. (2012) 'Residential energy-efficient technology adoption, energy conservation, knowledge, and attitudes: An analysis of European countries', Energy Policy, 49, pp. 616-628.

Miller, T. Bell, L. (2002). Chapter 3: Consenting to what? Issues of Access, Gate-Keeping and Informed Consent. In: Mauthner, M., Birch, J., Jessop, J. Miller, T. Qualitative Research, Sage: London.

Mitzner, T.L., Boron, J.B., Fausset, C.B., Adams, A.E., Charness, N., Czaja, S.J., Dijkstra, K., Fisk, A.D., Rogers, W.A. and Sharit, J. (2010) ‘Older adults talk technology: Technology usage and attitudes', Computers in Human Behavior, 26(6), pp. 1710-1721.

Murtagh, N., Gatersleben, B. and Uzzell, D. (2014) '20:60:20 - differences in energy behaviour and conservation between and within households with electricity monitors', PLOS ONE, 9(3), p.2019.

Neves, B. B. and Amaro, F. (2012) 'Too old for technology? How the elderly of Lisbon use and perceive ICT', The Journal of Community Informatics, 8 (1).

Nilsson, A., Bergstad, C.J., Thuvander, L., Andersson, D., Andersson, K. and Meiling, P. (2014) 'Effects of continuous feedback on households' electricity consumption: Potentials and barriers', Applied Energy, 122, pp. 17-23. 
Office for National Statistics (2014) Internet access - households and individuals: 2014.

https://www.ons.gov.uk/peoplepopulationandcommunity/householdcharacteristics/homeinterneta ndsocialmediausage/bulletins/internetaccesshouseholdsandindividuals/2014-08-07 [6/10/16].

Office for National Statistics (2016) Overview of the UK population: February 2016.

http://www.ons.gov.uk/peoplepopulationandcommunity/populationandmigration/populationestim ates/articles/overviewoftheukpopulation/february2016 [3/9/16].

Pace, S. (2012) 'Writing the self into research: Using grounded theory analytic strategies in autoethnography'. http://www.textjournal.com.au/speciss/issue13/Pace.pdf [12/11/16].

Petkov, P., Köbler, F., Foth, M. and Krcmar, H. (2011). 'Motivating domestic energy conservation through comparative, community-based feedback in mobile and social media', Proceedings of the 5th International Conference on Communities and Technologies, June 29-July 02, 2011, Brisbane, Australia.

Phillips, R and Johns, J. (2012). Chapter 7: Interviewing for Fieldwork In: Johns, J. and Phillips, R. (eds) Fieldwork for human geography. London, United Kingdom: SAGE Publications.

Saldaña, J. and Saldana, J. (2009) The coding manual for qualitative researchers. Los Angeles, CA: SAGE Publications.

Selwyn, N. (2004) 'The information aged: A qualitative study of older adults' use of information and communications technology', Journal of Aging Studies, 18(4), pp. 369-384.

Shove, E. (1998) 'Gaps, barriers and conceptual chasms: Theories of technology transfer and energy in buildings', Energy Policy, 26(15), pp. 1105-1112.

Shove, E. (2003) Comfort, cleanliness and convenience: The social organization of normality. Oxford, England: Berg Publishers. 
Shove, E. (2010) 'Beyond the ABC: Climate change policy and theories of social change', Environment and Planning, 42(6), pp. 1273-1285.

Shove, E. and Walker, G. (2014) 'What is energy for? Social practice and energy demand', Theory, Culture \& Society, 31(5), pp. 41-58.

Smart Energy GB (2016) About smart energy GB. https://www.smartenergygb.org/en/about-smart-energygb/about-smart-energy-gb [9/9/16].

Strengers, Y. (2008) 'Smart metering demand management programs: challenging the comfort and cleanliness habitus of households'. OZCHI, 8-12 December 2008. Cairns, Australia.

Strengers, Y. (2011) 'Negotiating everyday life: The role of energy and water consumption feedback', Journal of Consumer Culture, 11(3), pp. 319-338.

Valentine, G. (1997) 'Tell me about...using interviews as a research methodology' in R. Flowerdue and D. Martin (eds) Methods in Human Geography: A guide for students doing a research project. Edinburgh Gate: Addison Wesley Longman. Pp. 110-126.

Wallenborn, G., Orsini, M. and Vanhaverbeke, J. (2011) 'Household appropriation of electricity monitors', International Journal of Consumer Studies, 35(2), pp. 146-152.

Warde, A. (2005) 'Consumption and theories of practice', Journal of Consumer Culture, 5(2), pp. 131-153.

World Health Organisation (2016) Proposed working definition of an older person in Africa for the MDS project. http://www.who.int/healthinfo/survey/ageingdefnolder/en/ [24/8/16].

Wilhite, H. and Ling, R. (1995) 'Measured energy savings from a more informative energy bill', Energy and Buildings, 22(2), pp. 145-155. 